\title{
Paritaprevir/ritonavir-ombitasvir and dasabuvir, the 3D regimen for the treatment of chronic hepatitis $C$ virus infection: a concise review
}

This article was published in the following Dove Press journal:

Hepatic Medicine: Evidence and Research

18 May 2016

Number of times this article has been viewed

\author{
Trana Hussaini ${ }^{1,2}$ \\ 'Faculty of Pharmaceutical \\ Sciences, University of British \\ Columbia, Vancouver, BC, Canada; \\ ${ }^{2}$ Pharmaceutical Sciences, Vancouver \\ General Hospital, Vancouver, BC, \\ Canada
}

\begin{abstract}
The treatment for chronic hepatitis $\mathrm{C}$ has been revolutionized with the development of direct-acting antiviral agents. Several regimens have been approved and are currently used in clinical practice, treating a wide range of patient populations infected with hepatitis $\mathrm{C}$. The interferon-free combination of paritaprevir/ritonavir-ombitasvir and dasabuvir (PrOD or the three-drug [3D] regimen) with or without ribavirin is indicated for the treatment of chronic hepatitis $\mathrm{C}$ in both treatment-naïve and experienced patients infected with genotype 1, including those coinfected with HIV and patients post-liver transplantation. More recently, paritaprevir/ ritonavir-ombitasvir ( $\mathrm{PrO}$, or 2D regimen) has been approved in hepatitis $\mathrm{C}$ virus patients infected with genotype 4 . This review will summarize pharmacokinetic and clinical efficacy data for the $3 \mathrm{D}$ regimen in an attempt to help the clinicians delineate its place in the ever-increasing directacting antiviral armamentarium for the treatment of chronic hepatitis $\mathrm{C}$.
\end{abstract}

Keywords: hepatitis C, paritaprevir, ombitasvir, dasabuvir, 3D regimen

\section{Introduction}

An estimated 130 to 150 million people are infected with hepatitis C virus (HCV) worldwide with approximately 500,000 dying each year as a result of HCV complications such as cirrhosis and hepatocellular carcinoma. ${ }^{1}$ Previously, pegylated interferon (PEG-IFN) and ribavirin (RBV) were standard treatment for $\mathrm{HCV}$ infection with poor response rates, intolerable side effects, and prolonged treatment course. ${ }^{2,3}$ Fortunately, the development of direct-acting antivirals (DAAs) has revolutionized the therapeutic landscape for chronic hepatitis $\mathrm{C}$. Interferon containing regimens have quickly become obsolete as ever-increasing DAA combinations with high efficacy, nominal side effects, and short treatment courses become available. ${ }^{4}$ In fact in the past year, several new antiviral compounds have been approved by the regulatory agencies in Europe and the US. ${ }^{5}$ Unlike PEG-IFN and RBV with their nonspecific antiviral activity, DAAs target specific nonstructural (NS) proteins encoded by the single-stranded HCV RNA virus. These include the NS3/4A protease inhibitors, the NS5A inhibitors, and the NS5B polymerase inhibitors, which are further subdivided into nucleoside and nonnucleoside polymerase inhibitors.

Currently there are five regimens approved for the treatment of chronic hepatitis

Correspondence: Trana Hussain

Vancouver General Hospital,

855 West I2th Avenue, Vancouver, BC.

V5Z IM9, Canada

$\mathrm{Tel}+\mathrm{I} 6043284930$

Fax +l 6048755267

Email trana.hussaini@vch.ca
C genotype $1 .{ }^{6}$ The combination of sofosbuvir (NS5B polymerase inhibitor) and ledipasvir (NS5A inhibitor) coformulated as a single daily tablet regimen is the most widely used DAA combination approved by the US Food and Drug Administration (FDA). Simiprevir (NS3/4A inhibitor) and daclatasvir (NS5A inhibitor) are other DAAs submit your manuscript

Dovepress $f$ in $D$

http://dx.doi.org/1 0.2147/HMER.S72429
Hepatic Medicine: Evidence and Research 2016:8 61-68

(c) (i) (c) 2016 Hussaini. This work is published and licensed by Dove Medical Press Limited. The full terms of this license are available at https://www.dovepress.com/terms.php cc. ${ }_{\mathrm{BY}} \mathrm{NC}$ and incorporate the Creative Commons Attribution - Non Commercial (unported, v3.0) License (http://creativecommons.org/licenses/by-n/ 3.00 ). By accessing the work you hereby accept the Terms. Non-commercial uses of the work are permitted without any further permission from Dove Medical Press Limited, provided the work is properly attributed. For permission for commercial use of this work, please see paragraphs 4.2 and 5 of our Terms (https://www.dovepress.com/terms.php). 
approved to be used in combination with sofosbuvir. The three-drug (3D) regimen, comprising of ritonavir-boosted paritaprevir, ombitasvir, and dasabuvir (PrOD) with or without RBV is another DAA combination used for the treatment of HCV genotype 1. Finally, grazoprevir (NS3/4A)/elbasvir (NS5A) fixed-dose regimen is the latest HCV therapy to be approved by the FDA earlier this year. This review will summarize clinical pharmacology, pharmacokinetic characteristics, and the pivotal clinical trials that led to the approval of the $3 \mathrm{D}$ regimen, in an attempt to delineate its place in the ever-increasing DAA regimens available for the treatment of chronic hepatitis $\mathrm{C}$.

\section{Pharmacology and pharmacokinetics}

Paritaprevir (ABT-450), ombitasvir (ABT-267), and dasabuvir (ABT-333) are DAAs approved for interferonfree combination treatment of chronic HCV genotypes 1 and 4 infections. $^{7}$ Paritaprevir is an NS protein 3/4A protease inhibitor coformulated with a low dose of ritonavir, a potent CYP3A inhibitor, as a pharmacokinetic booster that increases peak and trough plasma drug concentrations of paritaprevir and its overall drug exposure, therefore allowing for once daily administration. Ombitasvir is an NS5A inhibitor and dasabuvir is a non-nucleoside NS5B polymerase inhibitor. Ombitasvir, paritaprevir, ritonavir, and dasabuvir are absorbed after oral administration and maximum serum concentration is reached at approximately 4 to 5 hours, and steady state concentration in $\sim 12$ days of dosing. ${ }^{7}$ Administration of ombitasvir, paritaprevir, ritonavir, and dasabuvir with a moderate-fat meal increases the mean area under the curve by $82 \%, 211 \%, 49 \%$, and $30 \%$, respectively; therefore, they should always be administered with a meal. All drugs are highly protein bound (97\% to $99 \%$ ). ${ }^{7}$ Hepatic metabolism and biliary excretion are the primary routes of elimination of paritaprevir, ombitasvir, and dasabuvir. Ombitasvir is predominantly metabolized by amide hydrolysis followed by oxidative metabolism with a relatively long half-life of 21 to 25 hours. Paritaprevir is predominantly metabolized by CYP3A4 and to a lesser extent by CYP3A5 and its half-life is $\sim 5.5$ hours when not combined with ritonavir. Paritaprevir interferes with bilirubin transporters OATP1B1/1B3 and can therefore lead to hyperbilirubinemia, especially when combined with RBV. ${ }^{7}$ Dasabuvir's major route of elimination is through CYP2C8 and to a lesser extent CYP3A with a half-life of 5.5 to 6 hours. Following a single-dose administration of paritaprevir $200 \mathrm{mg}$ with ritonavir $100 \mathrm{mg}$, ombitasvir $25 \mathrm{mg}$, and dasabuvir $400 \mathrm{mg}$, approximately $88 \%$ to $94.4 \%$ and $1.9 \%$ to $8.8 \%$ of the doses of the DAAs were eliminated in feces and urine, respectively. ${ }^{7}$ Due to minimal renal elimination, dosage adjustment is not required in renal dysfunction. However, since hepatic metabolism is the predominant route of elimination for all these agents, their pharmacokinetics will vary in chronic liver disease. ${ }^{8}$ The use of PrOD is contraindicated in patients with moderate-to-severe hepatic impairment (Child-Pugh B and C) based on reports of rapid onset of liver injury and hepatic decompensation when used in patients with cirrhosis. ${ }^{6,7}$

\section{Drug interactions}

Paritaprevir is an inhibitor of the OATP1B1 transporter and is metabolized primarily by CYP3A4. ${ }^{7,9}$ Ritonavir, an HIV protease inhibitor, is a potent inhibitor of CYP3A4 and is used as a pharmacological booster to increase the peak and trough concentrations and overall exposure of paritaprevir. Ritonavir is also a substrate, inhibitor, and inducer of several other enzymes and proteins (Table 1). ${ }^{10}$ The inclusion of ritonavir in PrOD greatly increases the potential for drug-drug interactions for this combination regimen. As such, medications that are extensively metabolized by CYP3A4 are contraindicated during therapy with PrOD. Similarly, potent CYP3A4 inducers such as antiepileptic medications will dramatically decrease exposure to paritaprevir and ritonavir, and therefore, their concomitant usage is contraindicated. Ombitasvir is

Table I Paritaprevir/ritonavir-ombitasvir and dasabuvir metabolizing enzymes and transporter proteins

\begin{tabular}{lllll}
\hline & Paritaprevir & Ritonavir & Ombitasvir & Dasabuvir \\
\hline $\begin{array}{l}\text { CYP450 enzymes } \\
\text { Substrate }\end{array}$ & CYP3A4 & CYP3A4, IA2, 2B6, 2D6 & CYP2C8>3A4 \\
$\begin{array}{l}\text { Inhibitor } \\
\text { Inducer }\end{array}$ & & CYP3A4, 2CI9, 2C8, 2C9, 2D6, 2EI & & CYP3A4 \\
$\begin{array}{l}\text { Transporter proteins } \\
\text { Substrate }\end{array}$ & CYPIA2, 2C9, 3A4 (weak) & & P-gP; BCRP \\
$\begin{array}{l}\text { Inhibitor } \\
\text { Inducer }\end{array}$ & P-gP; OATPIBI/3; BRCP & P-gP & P-gP & BCRP \\
Other enzymes & OATPIBI/3 & BCRP & BCRP & Inhibits UGTIAI Inhibits UGTIAI \\
\hline
\end{tabular}

Abbreviations: BCRP, breast cancer resistance protein; CYP, cytochrome P450; OATP, organic anion transporter protein; P-gP, P-glycoprotein; UGTIAI, uridine diphosphate glucuronyltransferase IAI. 
predominantly metabolized by hydrolysis followed by oxidation reactions. ${ }^{7}$ Dasabuvir is metabolized by CYP2C8 and to a lesser extent by CYP3A. ${ }^{7}$ Strong CYP2C8 inhibitors can increase levels of dasabuvir, and these agents are also contraindicated during PrOD therapy. Table 2 lists the most common drug-drug interactions with the $3 \mathrm{D}$ regimen.

\section{Summary of clinical trials Treatment-naïve without cirrhosis}

SAPPHIRE I was a Phase III international, multicenter, randomized, placebo-controlled trial that randomized treatment-naïve patients with HCV genotype 1 infection, in a 3:1 ratio to either active $3 \mathrm{D}$ regimen or placebo. ${ }^{11}$ Patients in the active group received a 12-week regimen consisting of a single-tablet coformulation of ritonavir boosted paritaprevir and ombitasvir (at a once daily dose of $150 \mathrm{mg}$ of paritaprevir, $100 \mathrm{mg}$ of ritonavir, and $25 \mathrm{mg}$ of ombitasvir) and dasabuvir (250 mg twice daily) with RBV (weight-based dosing, $1,000 \mathrm{mg} /$ day if $<75 \mathrm{~kg}$ or $1,200 \mathrm{mg} /$ day if $\geq 75 \mathrm{~kg}$ ). The primary end point was sustained virological response at 12 weeks after the end of treatment (SVR12). A total of 631 patients were randomized to receive $3 \mathrm{D}$ regimen $(\mathrm{N}=473)$ or placebo $(\mathrm{N}=158)$. The overall rate of SVR12 was $96.2 \%$ with $95.3 \%$ of patients infected with HCV genotype 1a achieving SVR in comparison to $98.0 \%$ in those with $\mathrm{HCV}$ genotype $1 \mathrm{~b}$. Virologic failure during treatment and relapse

Table 2 Paritaprevir/ritonavir-ombitasvir and dasabuvir drug-drug interactions

\begin{tabular}{|c|c|c|}
\hline Drug class & Drug(s) within the class & Comment \\
\hline Alpha I-adrenoreceptor antagonist & Alfuzosin $\mathrm{HCl}$ & Contraindicated due to risk of hypotension \\
\hline \multirow[t]{2}{*}{ Anti arrhythmics } & Amiodarone, bepridil, disopyramide, flecainide, lidocaine & $\uparrow$ Concentration of anti arrhythmics \\
\hline & (systemic), mexiletine, propafenone, quinidine & TDM recommended when available \\
\hline Anticonvulsants & Carbamazepine, phenytoin, phenobarbital & Contraindicated as $\downarrow$ PrOD exposure \\
\hline \multirow[t]{2}{*}{ Antifungals } & Ketoconazole & Maximum daily dose of ketoconazole $200 /$ day \\
\hline & Voriconazole & Contraindicated due to $\downarrow$ voriconazole \\
\hline Antihyperlipidemic agent & Gemfibrozil & Contraindicated due to $\uparrow$ dasabuvir \\
\hline Antimycobacterial & Rifampin & Contraindicated as $\downarrow$ PrOD exposure \\
\hline \multirow[t]{2}{*}{ Calcium channel blockers } & Amlodipine & Reduce amlodipine by $50 \%$ \\
\hline & & Avoid felodipine and nisoldipine \\
\hline \multirow[t]{2}{*}{ Corticosteroids (inhaled) } & Fluticasone & Reduced serum concentrations of cortisol \\
\hline & & Consider alternative corticosteroids \\
\hline Ergot derivatives & $\begin{array}{l}\text { Ergotamine, dihydroergotamine, ergonovine, } \\
\text { methylergonovine }\end{array}$ & Contraindicated due to risk of ergot toxicity \\
\hline Herbal product & St John's Wort (Hypericum perforatum) & Contraindicated as $\downarrow$ PrOD exposure \\
\hline \multirow[t]{5}{*}{ HIV-antivirals } & Atazanavir, atazanavir/r & Unboosted atazanavir 300 mg daily acceptable \\
\hline & Darunavir/r & $\downarrow$ Darunavir trough - not recommended \\
\hline & Lopinavir/r & $\begin{array}{l}\uparrow \text { GI side effects of lopinavir and } \downarrow \text { paritaprevir - not } \\
\text { recommended }\end{array}$ \\
\hline & Efavirenz & $\uparrow$ Adverse events with efavirenz - not recommended \\
\hline & Rilpivirine & $\begin{array}{l}\uparrow \text { Rilpivirine and may prolong QTC interval - not } \\
\text { recommended }\end{array}$ \\
\hline \multirow[t]{2}{*}{ HMG-CoA reductase } & Lovastatin, simvastatin & Contraindicated \\
\hline & Pravastatin, rosuvastatin & Dosage reduction recommended \\
\hline \multirow[t]{4}{*}{ Immunosuppressants } & Cyclosporine & Significant $\uparrow$ in Cyclosporine levels \\
\hline & & $\downarrow$ Cyclosporine dose to $20 \%$ of current dose \\
\hline & & and monitor blood concentrations \\
\hline & Tacrolimus & $\begin{array}{l}\text { Significant } \uparrow \text { in tacrolimus exposure requiring dosage } \\
\text { adjustment. Typical dose is } 0.5 \mathrm{mg} \text { every } 7 \text { days }\end{array}$ \\
\hline Neuroleptics & Pimozide & Contraindicated due to risk of QTC prolongation \\
\hline \multirow[t]{3}{*}{ Oral contraceptives } & Ethinyl estradiol/norgestimate & Contraindicated \\
\hline & & $\downarrow$ Paritaprevir/ritonavir and dasabuvir concentration \\
\hline & & Elevated LFTs \\
\hline PDE5 inhibitor & $\begin{array}{l}\text { Sildenafil when dosed for the treatment of pulmonary } \\
\text { arterial hypertension }\end{array}$ & Contraindicated due to $\downarrow$ sildenafil exposure \\
\hline \multirow[t]{2}{*}{ Proton pump inhibitors } & Omeprazole & $\downarrow$ Omeprazole concentration \\
\hline & & Avoid $>40 \mathrm{mg} /$ day of omeprazole \\
\hline Sedatives/hypnotics & Triazolam; orally administered midazolam & $\begin{array}{l}\text { Contraindicated due to } \uparrow \text { risk of side effects, } \\
\text { sedation, and respiratory depression }\end{array}$ \\
\hline
\end{tabular}

Abbreviations: LFTs, liver function tests; PrOD, Paritaprevir/ritonavir-ombitasvir and dasabuvir; TDM, therapeutic drug monitoring; GI, gastrointestinal. 
after treatment occurred in $0.2 \%$ and $1.5 \%$, respectively, all demonstrating resistance associated variants to one or more of the three DAAs included in this regimen. The treatment was well tolerated with fatigue and headache being the most common adverse drug reactions (ADR). Hyperbilirubinemia occurred in $2.8 \%$ of patients, but it resolved without treatment discontinuation. Anemia grade 1 (normal hemoglobin [Hgb] to $100 \mathrm{~g} / \mathrm{L}$ ) and grade $2(\mathrm{Hgb} 80-100 \mathrm{~g} / \mathrm{L}$ ) occurred in $47.5 \%$ and $2.5 \%$ of patients, respectively. The rate of discontinuation due to adverse events was $0.6 \%$.

PEARL-III and -IV studies established the role of RBV for the treatment of $\mathrm{HCV}$ in genotype 1a patients and its dispensability for the treatment-naïve non-cirrhotic genotype $1 \mathrm{~b}$ patients. ${ }^{12}$ They were both Phase III, randomized, openlabel trials evaluating safety and efficacy of PrOD with or without RBV for 12 weeks in treatment-naïve patients with chronic HCV genotype 1b (PEARL-III) or genotype 1a (PEARL-IV). Four hundred and nineteen patients with $\mathrm{HCV}$ genotype $1 \mathrm{~b}$ infection (PEARL-III study) and 305 patients with genotype 1a infection (PEARL-IV study) were randomly assigned to 12 weeks of paritaprevir/ritonavir-ombitasvir (at a once daily dose of $150 \mathrm{mg}$ of paritaprevir, $100 \mathrm{mg}$ of ritonavir, and $25 \mathrm{mg}$ of ombitasvir), dasabuvir (250 $\mathrm{mg}$ twice daily), plus weight based RBV or matching placebo for RBV. $\mathrm{RBV}$ administration did not enhance response rates in $\mathrm{HCV}$ genotype $1 \mathrm{~b}$ infected patients with SVR12 rates of $99.5 \%$ with RBV and 99.0\% without RBV. However, the SVR12 rates were higher for $\mathrm{HCV}$ genotype 1a infected patients who received RBV vs those who received placebo $(97.0 \%$ and $90.2 \%$, respectively). The rate of virologic failure was higher in the RBV-free group than in the RBV group (7.8\% vs $2.0 \%$ ) in patients with genotype $1 \mathrm{a}$ infection. Grade 1 anemia $(\mathrm{Hgb}<$ lower limit of normal [LLN]) was more frequent in patients who received RBV vs placebo, but severe anemia was uncommon. The most common adverse events reported in all groups were fatigue and headache.

Based on the earlier Phase III studies, it is recommended to use PrOD plus RBV for 12 weeks in treatment-naïve non-cirrhotic HCV genotype 1a patients and 12 weeks of PrOD alone in treatment-naïve genotype $1 \mathrm{~b}$ patients (Tables 3 and 4).

\section{Treatment-experienced without cirrhosis}

SAPPHIRE II was a Phase III, multicenter, randomized, open-label trial evaluating safety and efficacy of 3D regimen plus RBV in treatment-experienced non-cirrhotic patients with chronic HCV genotype $1 .{ }^{13}$ Two hundred and ninetyseven patients with history of prior treatment with $\mathrm{PEG} / \mathrm{RBV}$ received 12 weeks of $3 \mathrm{D}$ in addition to weight-based RBV achieving an overall SVR12 rate of $96.3 \%$ (96\% in patients with genotype $1 \mathrm{a}$ and $96.7 \%$ in patients with genotype $1 \mathrm{~b}$ ). The SVR12 rates were $95.3 \%$ among patients with a prior relapse, $100 \%$ in patients with a prior partial response, and $95.2 \%$ among patients with a prior null response. None of the patients had virologic failure during treatment; however, seven patients had a post treatment viral relapse, all displaying resistance associated variants. Pruritus was the most frequent adverse event, being reported in $13.8 \%$ of patients. Three patients $(1.0 \%)$ discontinued the study drugs owing to adverse events. Hgb values of grade $2(80$ to $<100 \mathrm{~g} / \mathrm{L})$ and grade 3 ( 65 to $<80 \mathrm{~g} / \mathrm{L}$ ) occurred in $4.7 \%$ and $0.3 \%$ of patients, respectively.

PEARL II was a Phase III, randomized, multicenter, open-label trial that evaluated whether RBV is necessary in combination with PrOD in treatment-experienced patients with chronic $\mathrm{HCV}$ g1b. ${ }^{14}$ A total of 179 patients with $\mathrm{HCV}$ genotype $1 \mathrm{~b}$ infection, without cirrhosis but previously treated with PEG-IFN and RBV, were randomized to receive either 12 weeks of PrOD plus RBV $(\mathrm{N}=88)$ or PrOD alone $(\mathrm{N}=91)$. The SVR12 rate was $96.9 \%$ in the PrOD plus RBV group and $100 \%$ in the PrOD regimen alone group. The most common adverse events were fatigue $(31.9 \%$ vs $15.8 \%$ ) and headache (24.2\% vs $23.2 \%)$ in PrOD plus RBV and PrOD groups, respectively. As expected, decreases in $\mathrm{Hgb}$ level to less than the LLM were more frequent in the PrOD plus RBV group (42\% vs 5.5\%). Two patients (1.1\%) discontinued the study owing to adverse events, both in $3 \mathrm{D}$ plus RBV group.

Based on the results of SAPHIRE II and PEARL II, it is recommended to use PrOD plus RBV for 12 weeks in treatment-experienced non-cirrhotic HCV genotype 1a patients and 12 weeks of PrOD in treatment-experienced genotype $1 \mathrm{~b}$ patients (Tables 3 and 4 ).

\section{Treatment-naïve or experienced with compensated cirrhosis}

TURQUOISE II was a Phase III, randomized, open-label trial that established treatment duration for the HCV infected patients with compensated cirrhosis. ${ }^{15}$ In this study, 380 patients with Child-Pugh class A cirrhosis were randomized to receive either 12 or 24 weeks of PrOD plus RBV. Approximately two-third of the patients had genotype 1a (67.3\% in 12-week group and $70.3 \%$ in 24 week group) and more than half were previously treated with PEG-IFN/RBV with approximately $60 \%$ having had previous null response. The overall SVR12 rate was 91.8\% (191/208) and 95.9\% 
Table 3 Summary of pivotal clinical trials

\begin{tabular}{|c|c|c|c|c|}
\hline Patient population & Study name/design & $\mathbf{N}$ & Treatment arm(s) & SVR (\%) \\
\hline \multirow[t]{9}{*}{ Treatment-naïve non-cirrhotic } & SAPPHIRE-I"I & 631 & Arm I: PrOD + RBV, 12 weeks & SVRI 2 by GT (Arm I) \\
\hline & randomized, double-blind, & & Arm 2: Placebo & GT Ia - 307/322 (95\%) \\
\hline & placebo-controlled & & & GT Ib - |48/I5I (98\%) \\
\hline & PEARL-III $(G T \text { Ib })^{12}$ & 419 & Arm I: PrOD + RBV, 12 weeks & SVRI2 \\
\hline & randomized, double-blind & & Arm 2: PrOD, 12 weeks & Arm I - 209/210 (I00\%) \\
\hline & & & & Arm 2 - 209/209 (100\%) \\
\hline & PEARL-IV (GT Ia $)^{12}$ & 305 & Arm I: PrOD + RBV, 12 weeks & SVRI2 \\
\hline & randomized, double-blind & & Arm 2: PrOD, 12 weeks & Arm I - 97/I00 (97\%) \\
\hline & & & & Arm 2 - I85/205 (90\%) \\
\hline \multirow{6}{*}{$\begin{array}{l}\text { Treatment-experienced non- } \\
\text { cirrhotic }\end{array}$} & SAPPHIRE-II (GT Ib) $)^{13}$ & 394 & Arm I: PrOD + RBV, 12 weeks & SVRI2 by GT (Arm I) \\
\hline & randomized, double-blind, & & Arm 2: Placebo & GT Ia - I66/I73 (96\%) \\
\hline & placebo-controlled & & & GT Ib - II I/I 23 (97\%) \\
\hline & PEARL-III & 186 & Arm I: PrOD + RBV, 12 weeks; & SVRI2 \\
\hline & randomized, open-label & & Arm 2: PrOD, 12 weeks & Arm I - 85/88 (97\%); \\
\hline & & & & Arm $2-91 / 91$ (100\%) \\
\hline Compensated cirrhosis & TURQUOISE-III5 & 380 & Arm I: PrOD + RBV, 12 weeks & Overall SVRI2 \\
\hline \multirow[t]{11}{*}{ treatment-naïve or experienced } & randomized, open-label & & Arm 2: PrOD + RBV, 24 weeks & Arm I - 19I/208 (91.8\%) \\
\hline & & & & Arm 2 - I65/I72 (95.9\%) \\
\hline & & & & SVRI 2 by GT \\
\hline & & & & GT la \\
\hline & & & & Arm I - I24/I 40 (88.6\%) \\
\hline & & & & Arm $2-114 / 121$ (94.2\%) \\
\hline & & & & GT Ib \\
\hline & & & & Arm I - $67 / 68$ (98.5\%) \\
\hline & & & & Arm $2-5 \mathrm{I} / 5 \mathrm{I}(100 \%)$ \\
\hline & TURQUOISE-III'16 & 60 & PrOD, 12 weeks & SVRI2 \\
\hline & single arm open-label & & & $60 / 60(100 \%)$ \\
\hline \multirow[t]{3}{*}{ HIV coinfection } & TURQUOISE-II7 & 63 & Arm I: PrOD + RBV, 12 weeks & SVRI2 \\
\hline & randomized, open-label & & Arm 2: PrOD + RBV, 24 weeks & Arm I - 29/3I (94\%) \\
\hline & & & & Arm $2-29 / 32(91 \%)$ \\
\hline \multirow[t]{2}{*}{ Post-liver transplant } & CORAL I'18 & 34 & PrOD + RBV, 24 weeks & SVR24 \\
\hline & open label single arm & & & $33 / 34(97 \%)$ \\
\hline Genotype 4 & PEARL-I' & 320 & $\mathrm{TN}$ & \\
\hline non-cirrhotic treatment-naïve & randomized, open- label & & Arm I: $\operatorname{PrO}+\mathrm{RBV}, 12$ weeks & Arm I - 42/42 (100\%) \\
\hline \multirow[t]{3}{*}{ or experienced } & & & Arm 2: PrO, 12 weeks & Arm $2-40 / 44$ (91\%) \\
\hline & & & TE & \\
\hline & & & $\mathrm{PrO}+\mathrm{RBV}, 12$ weeks & $49 / 49(100 \%)$ \\
\hline Severe renal impairment & RUBY-I (GT Ia) ${ }^{20,21}$ & 40 & PrOD + RBV & $\begin{array}{l}\text { Results pending as } \\
\text { ongoing study }\end{array}$ \\
\hline
\end{tabular}

Abbreviations: GT, genotype; PrOD, Paritaprevir/ritonavir-ombitasvir and dasabuvir; RBV, ribavirin; SVRI2, sustained virological response at I2 weeks after the end of treatment; TE, treatment-experienced; TN, treatment-naïve; SVR, sustained virological response.

(165/172) in 12- and 24-week groups, respectively. The SVR rates were higher with 24 weeks of treatment in patients with genotype 1a (94.2\% vs $88.6 \%)$ but not appreciably in patients with genotype $1 \mathrm{~b}(98.5 \%$ vs $100 \%)$. Treatmentexperienced patients with genotype 1a had a higher response rate with 24 weeks of therapy, especially in those with prior null response ( $80 \%$ vs $92.9 \%$ ); however, the same trend was not observed in patients infected with genotype $1 \mathrm{~b}$. Treatment was well tolerated with $2.1 \%$ of patients discontinuing treatment owing to adverse events. As with previous studies, fatigue and headaches were the most common side effects. Grade $1 \mathrm{Hgb}$ drop ( $100 \mathrm{~g} / \mathrm{L}$ to lower than LLN) was observed in $49.5 \%$ and $56.4 \%$ of 12 - and 24 -week groups, respectively. Similarly, grade 2 anemia ( $80-100 \mathrm{~g} / \mathrm{L}$ ) occurred in $5.8 \%$ and $10.5 \%$. Grades 3 and $4 \mathrm{Hgb}$ drops were uncommon.

TURQUOISE III was a Phase IIIb open-label trial that demonstrated optimal response rates can be achieved in treatment-experienced cirrhotic patients with $\mathrm{HCV}$ genotype $1 \mathrm{~b}$ without the addition of $\mathrm{RBV}^{16}$ In this single-arm openlabel trial, 60 patients with genotype $1 \mathrm{~b}$ received 12 weeks of PrOD regimen. All patients had compensated cirrhosis and 55\% were PEG-IFN/RBV treatment-experienced. All 60 patients (100\%) achieved SVR 12. Most adverse events were mild to moderate and included, fatigue $(21.7 \%)$, diarrhea 
Table 4 Current American Association for the Study of Liver Diseases (AASLD) and Infectious Diseases Society of America (IDSA) recommendations for treatment regimen and duration with $\mathrm{PrOD}$ or $\mathrm{PrO}$ with or without ribavirin

\begin{tabular}{lll}
\hline $\begin{array}{l}\text { Genotypel } \\
\text { treatment } \\
\text { history }\end{array}$ & Non-cirrhotic & Compensated cirrhosis \\
\hline GT Ia; TN & PrOD + RBV for I2 weeks & PrOD + RBV for 24 weeks \\
GT Ia; TE & PrOD + RBV for I2 weeks & PrOD + RBV for 24 weeks \\
GT Ib; TN & PrOD for I2 weeks & PrOD for I2 weeks \\
GT Ib; TE & PrOD for I2 weeks & PrOD for I2 weeks \\
GT 4; TN & PrO + RBV for I2 weeks & Not recommended \\
\hline
\end{tabular}

Abbreviations: GT,genotype;PrOD, Paritaprevir/ritonavir-ombitasvir and dasabuvir; PrO, paritaprevir/ritonavir-ombitasvir; RBV, ribavirin; TE, treatment-experienced; $T N$, treatment-naïve.

(20.0\%), and headaches (18.3\%). One patient experienced hypotension and syncope leading to hospitalization due to drug-drug interactions between ritonavir and antihypertensive medications.

Based on the results of these studies, it is recommended that cirrhotic patients with genotype 1a be treated with 24 weeks of PrOD plus RBV, whereas cirrhotic patients with genotype $1 \mathrm{~b}$ should only receive 12 weeks of PrOD without the addition of RBV (Tables 3 and 4).

\section{HIV coinfected}

TURQUOISE-I was a Phase 2/3, randomized, multicenter (US and Puerto Rico), open-label trial evaluating the safety and efficacy of PrOD plus RBV for 12 or 24 weeks in treatment-naïve and experienced patients coinfected with $\mathrm{HCV}$ genotype 1 and HIV, including those with compensated cirrhosis. ${ }^{17}$ Patients were included if CD 4 count was $\geq 200$ cells/ $\mathrm{mm}^{3}$ (or CD4\% $\geq 14$ ) and HIV RNA level $<40$ copies $/ \mathrm{mL}$ and were receiving a stable antiretroviral regimen of atazanavir or raltegravir plus 2 nucleos(t)ide analog reverse transcriptase inhibitors for at least 8 weeks before screening. Sixty-three patients were randomized to receive 12 weeks $(\mathrm{N}=31)$ or 24 weeks $(\mathrm{N}=32)$ of ProD plus $\mathrm{RBV}$, regimen. The majority of patients (89\%) were infected with HCV genotype 1a. Approximately $65 \%$ of patients were treatment-naïve, $16 \%$ were previous null responders, and $19 \%$ were cirrhotic (Child-Pugh A) in each group. The SVR12 rates were 94\% (29/31) and 91\% (29/32) after 12 or 24 weeks of treatment with 3D plus RBV, respectively. Of the five patients who did not achieve SVR, one patient withdrew consent, one patient relapsed at posttreatment week 4 , one patient experienced on-treatment $\mathrm{HCV}$ virologic breakthrough at week 16 , and two patients were believed to have been re-infected with HCV. The most common adverse events were fatigue
(48\%), insomnia (19\%), nausea (17\%), and headache (16\%). Hyperbilirubinemia occurred in 17 patients, but the majority of them $(15 / 17)$ were receiving atazanavir-inclusive antiretrovirals. Grade $2 \mathrm{Hgb}$ decline $(<100-80 \mathrm{~g} / \mathrm{L})$ was observed in four $(13 \%)$ and three $(9 \%)$ patients in the 12- and 24-week treatment groups, respectively.

\section{Post-liver transplantation}

CORAL-I was a Phase 2, multicenter, open-label, single-arm trial evaluating safety and efficacy of 24 weeks of PrOD plus RBV in liver transplant recipients with recurrent $\mathrm{HCV}$ genotype $1 .{ }^{18}$ The patients had to be $>1$ year posttransplant, treatment-naïve after transplantation, but could have been treated with PEG-IFN/RBV prior to transplantation. Only patients with no fibrosis or mild fibrosis $(\leq F 2$ on liver biopsy) were included in this study. All patients received 24 weeks of PrOD in addition to RBV. RBV dosing was left to the discretion of the investigator because of the known risk of RBV-related hematologic toxic effects in transplant recipients. Patients receiving cyclosporine, tacrolimus, and prednisone up to $5 \mathrm{mg} /$ day were included in this study. Due to known drug-drug interactions between calcineurin inhibitors (CNIs) and the protease inhibitors, prespecified dosage adjustments for CNIs were recommended. Thirtyfour patients, the majority of whom were infected with $\mathrm{HCV}$ genotype 1a (85\%) and $71 \%$ previously treated with PEGIFN plus RBV were included in this study. All patients except one achieved SVR12 and SVR24 (97\%). The most common adverse events were fatigue, headache, and cough. Grade 3 Hgb drop occurred in one patient, but 19 (56\%) patients required RBV dosage adjustments and five patients (15\%) required erythropoietin; none of the patients required a blood transfusion. CNI serum levels were monitored, and dosages were modified to maintain therapeutic levels; no episode of graft rejection occurred during the study.

\section{Genotype 4}

PEARL-I was a Phase IIb, randomized, open-label trial evaluating the single tablet formulation of two-drug (2D) regimen, paritaprevir/ritonavir-ombitasvir (PrO), with or without RBV, for 12 weeks in non-cirrhotic treatment-naïve or experienced patients with chronic $\mathrm{HCV}$ genotype $4 .{ }^{19}$ Overall 135 patients were enrolled including 86 treatment-naïve and 49 treatmentexperienced patients. Half of the treatment-naïve (42) and all treatment-experienced patients received RBV in addition to PrO. All patients who received PrO plus RBV including treatment-experienced patients achieved SVR12. In the treatment-naïve group who received PrO without RBV, all but four 
achieved SVR12 with three documented virological failures (one virological breakthrough and two relapses). All three patients had resistance-associated variants present at the time of failure that were not present at baseline. The most common treatment related adverse events were headache $(29 \%-33 \%)$, asthenia (24\%-33\%), fatigue (7\%-18\%), insomnia (5\%-16\%), and nausea $(9 \%-17 \%)$. Four patients out of $91(4 \%)$ receiving $\mathrm{RBV}$ required dosage modification for $\mathrm{Hgb}$ level $<100 \mathrm{~g} / \mathrm{L}$.

\section{Patients with advanced renal impairment}

RUBY-1 trial is an ongoing Phase IIIb, randomized, openlabel trial, evaluating the safety and efficacy of 3D plus/minus RBV in HCV genotype 1 patients with advanced stage 4 or 5 chronic kidney disease (CKD) including those receiving hemodialysis. ${ }^{20,21}$

Cohort 1 of RUBY-I enrolled 20 treatment-naïve, noncirrhotic adults with advanced CKD (65\% receiving hemodialysis) to receive 12 weeks of 3D plus RBV (genotype 1a) or 3D (genotype $1 \mathrm{~b}$ ). RBV was dosed at $200 \mathrm{mg}$ once daily for genotype 1a patients. Preliminary results have revealed that ten out of ten patients achieved SVR4, and of those, two patients reached SVR12. As expected, the use of RBV was associated with an increased drop in Hgb levels, nine of the 13 genotype 1a patients required RBV dosage reduction, and eight required interruption of RBV dosing. Four of eight patients also required erythropoietin treatment during the first 7 weeks of therapy. There was one case of $\mathrm{Hgb}<80 \mathrm{~g} / \mathrm{L}$, but no blood transfusions were required. The mean drug concentrations of all DAA drugs (PrOD) were within the range that was observed with previous pharmacokinetic studies in healthy volunteers. Although the final study results have not been published yet, the American Association for the Study of Liver Diseases guidance document has listed the $3 \mathrm{D}$ regimen with or without $\mathrm{RBV}$ as an option in patients with advanced CKD. ${ }^{6}$

\section{Conclusion}

Although the PrOD regimen has demonstrated a high level of efficacy in a wide range of patients with chronic hepatitis $\mathrm{C}$, its use in clinical practice remains limited. In fact, the combination of ledipasvir/sofosbuvir, NS5A/NS5B, remains one of the most widely used first-line regimens. There are many reasons for this preferential usage in the real-world setting. First, ledipasvir/sofosbuvir is a single tablet daily regimen, whereas PrOD requires administering four tablets, not including $\mathrm{RBV}$, on a twice daily interval. This more complex regimen with higher pill burden could potentially affect compliance and compromise treatment success. Additionally, PrOD is commonly combined with RBV, which car- ries a greater risk of side effects and requires more intense monitoring, especially in the setting of renal dysfunction. Also, the inclusion of ritonavir in the PrOD combination renders this regimen susceptible to multiple drug-drug interactions, especially in the transplant population and in those coinfected with HIV. Finally, PrOD cannot be used in cirrhotic patients with Child-Pugh Class B or C due to risk of decompensation and further liver injury. ${ }^{6}$ For now, patients infected with genotype 4 or those with advanced CKD may be potential target populations for the PrOD regimen. However, as the landscape for HCV therapy changes, PrOD can quickly lose its place in therapy. Elbasvir/grazoprevir single tablet regimen was recently approved for the treatment of patients with HCV genotypes 1 and 4 including those with advanced CKD. ${ }^{6,22,23}$ This simple once daily regimen does not require the use of RBV and has produced excellent SVR rates in Phase III clinical trials. ${ }^{22}$ More recently, velpatasvir, a pangenotypic NS5A inhibitor in combination with sofosbuvir, as a single tablet regimen, has shown impressive SVR rates in both treatment-experienced and naïve patients infected with HCV genotypes 1 through 6. ${ }^{24,25}$ Therefore, as simpler, pangenotypic, RBV-free regimens become available, demand for PrOD will likely further decline.

\section{Disclosure}

The author reports no conflicts of interest in this work.

\section{References}

1. who.int [homepage on the Internet]. Hepatitis C. Fact sheet 164. World Health Organization; 2015. Available from: http://www.who.int/ mediacentre/factsheets/fs164/en/. Accessed April 21, 2016.

2. Fried MW, Shiffman ML, Reddy KR, et al. Peginterferon alfa-2a plus ribavirin for chronic hepatitis C virus infection. $N$ Engl $J$ Med. 2002;347(13):975-982.

3. Manns MP, McHutchison JG, Gordon SC, et al. Peginterferon alfa-2b plus ribavirin compared with interferon alfa- $2 \mathrm{~b}$ plus ribavirin for initial treatment of chronic hepatitis C: a randomised trial. Lancet. 2001;358(9286):958-965.

4. Asselah T, Boyer N, Saadoun D, Martinot-Peignoux M, Marcellin P. Direct-acting antivirals for the treatment of hepatitis $\mathrm{C}$ virus infection: optimizing current IFN-free treatment and future perspectives. Liver Int. 2016;36 (Suppl 1):47-57.

5. Wedemeyer H. Towards interferon-free treatment for all $\mathrm{HCV}$ genotypes. Lancet. 2015;385(9986):2443-2445.

6. hcvguidelines.org [homepage on the Internet]. Initial treatment of hev infection. American Association for the Study of Liver Diseases and the Infectious Diseases Society of America [updated February 24, 2016]. Available from: http://www.hcvguidelines.org/full-report/initialtreatment-hcv-infection. Accessed April 22, 2016.

7. AbbVie Corporation. Product monograph including patient medication information PrHOLKIRA ${ }^{\mathrm{TM}}$ PAK. AbbVie Corporation; 2016. Available from: http://www.abbvie.ca/content/dam/abbviecorp/ca/english/docs/ HOLKIRA_PAK_PM_EN.pdf. Accessed April 22, 2016.

8. Khatri A, Menon RM, Marbury TC, et al. Pharmacokinetics and safety of co-administered paritaprevir plus ritonavir, ombitasvir, and dasabuvir in hepatic impairment. J Hepatol. 2015;63(4):805-812. 
9. Menon RM, Badri PS, Wang T, et al. Drug-drug interaction profile of the all-oral anti-hepatitis $\mathrm{C}$ virus regimen of paritaprevir/ritonavir, ombitasvir, and dasabuvir. J Hepatol. 2015;63(1):20-29.

10. Burgess S, Partovi N, Yoshida EM, Erb SR, Azalgara VM, Hussaini T. Drug interactions with direct-acting antivirals for hepatitis C: implications for HIV and transplant patients. Ann Pharmacother. 2015;49(6):674-687.

11. Feld JJ, Kowdley KV, Coakley E, et al. Treatment of HCV with ABT-450/r-ombitasvir and dasabuvir with ribavirin. $N$ Engl J Med. 2014;370(17):1594-1603.

12. Ferenci P, Bernstein D, Lalezari J, et al. ABT-450/r-ombitasvir and dasabuvir with or without ribavirin for HCV. $N$ Engl J Med. 2014;370(21):1983-1992.

13. Zeuzem S, Jacobson IM, Baykal T, et al. Retreatment of HCV with ABT-450/r-ombitasvir and dasabuvir with ribavirin. $N$ Engl J Med. 2014;370(17):1604-1614.

14. Andreone P, Colombo MG, Enejosa JV, et al. ABT-450, ritonavir, ombitasvir, and dasabuvir achieves $97 \%$ and $100 \%$ sustained virologic response with or without ribavirin in treatment-experienced patients with HCV genotype 1b infection. Gastroenterology. 2014;147(2): 359-365.e1.

15. Poordad F, Hezode C, Trinh R, et al. ABT-450/r-ombitasvir and dasabuvir with ribavirin for hepatitis $\mathrm{C}$ with cirrhosis. $N$ Engl J Med. 2014;370(21):1973-1982.

16. Feld JJ, Moreno C, Trinh R, et al. Sustained virologic response of $100 \%$ in $\mathrm{HCV}$ genotype $1 \mathrm{~b}$ patients with cirrhosis receiving ombitasvir/paritaprevir/r and dasabuvir for 12 weeks. J Hepatol. 2016;64(2):301-307.

17. Sulkowski MS, Eron JJ, Wyles D, et al. Ombitasvir, paritaprevir co-dosed with ritonavir, dasabuvir, and ribavirin for hepatitis $\mathrm{C}$ in patients co-infected with HIV-1: a randomized trial. JAMA. 2015;313(12):1223-1231.
18. Kwo PY, Mantry PS, Coakley E, et al. An interferon-free antiviral regimen for $\mathrm{HCV}$ after liver transplantation. $N \mathrm{Engl} \mathrm{J} \mathrm{Med.}$ 2014;371(25):2375-2382.

19. Hézode C, Asselah T, Reddy KR, et al. Ombitasvir plus paritaprevir plus ritonavir with or without ribavirin in treatment-naive and treatment-experienced patients with genotype 4 chronic hepatitis $\mathrm{C}$ virus infection (PEARL-I): a randomised, open-label trial. Lancet. 2015;385(9986):2502-2509.

20. Pockros PJ, Reddy KR, Mantry PS, et al. RUBY-I: Ombitasvir/ paritaprevir/ritonavir + dasabuvir +/- ribavirin in non-cirrhotic $\mathrm{HCV}$ genotype 1-infected patients with severe renal impairment or end-stage renal disease. Hepatology conference: 66th Annual Meeting of the American Association for the Study of Liver Diseases: The Liver Meeting; Nov 13-19, 2015; San Francisco, CA. 2015;62:716A-717A.

21. Pockros PJ, Reddy KR, Mantry PS, et al. LO1: Safety of ombitasvir/ paritaprevir/ritonavir plus dasabuvir for treating HCV GT1 infection in patients with severe renal impairment or end-stage renal disease: The RUBY-I study. J Hepatol. 2015;62(Suppl 2):S257.

22. Roth D, Nelson DR, Bruchfeld A, et al. Grazoprevir plus elbasvir in treatment-naive and treatment-experienced patients with hepatitis $C$ virus genotype 1 infection and stage 4-5 chronic kidney disease (the C-SURFER study): a combination phase 3 study. Lancet. 2015;386(10003):1537-1545.

23. Maruyama A, Partovi N, Yoshida EM, Erb SR, Azalgara VM, Hussaini T. A review of direct-acting antivirals for the treatment of hepatitis $\mathrm{C}$ in patients with advanced chronic kidney disease. Nephrol Dial Transplant. Epub 2015 Oct 19.

24. Feld JJ, Jacobson IM, Hezode C, et al. Sofosbuvir and velpatasvir for HCV genotype 1, 2, 4, 5, and 6 infection. N Engl J Med. 2015;373(27): 2599-2607.

25. Foster GR, Afdhal N, Roberts SK, et al. Sofosbuvir and velpatasvir for HCV genotype 2 and 3 infection. N Engl J Med. 2015;373(27):2608-2617.
Hepatic Medicine: Evidence and Research

\section{Publish your work in this journal}

Hepatic Medicine: Evidence and Research is an international, peerreviewed, open access journal covering all aspects of adult and pediatric hepatology in the clinic and laboratory including the following topics: Pathology, pathophysiology of hepatic disease; Investigation and treatment of hepatic disease; Pharmacology of drugs used for

\section{Dovepress}

the treatment of hepatic disease. Issues of patient safety and quality of care will also be considered. The manuscript management system is completely online and includes a very quick and fair peer-review system, which is all easy to use. Visit http://www.dovepress.com/ testimonials.php to read real quotes from published authors. 